\title{
Relationships of cochlear coiling shape and hearing frequencies in cetaceans, and the occurrence of infrasonic hearing in Miocene Mysticeti
}

\author{
Indira S. Ritsche ${ }^{1}$, Julia M. Fahlke ${ }^{1}$, Frank Wieder ${ }^{2}$, André Hilger $^{3}$, Ingo Manke ${ }^{3}$, and Oliver Hampe ${ }^{1}$ \\ ${ }^{1}$ Museum für Naturkunde - Leibniz-Institut für Evolutions- und Biodiversitätsforschung, Invalidenstraße 43, \\ 10115 Berlin, Germany \\ ${ }^{2}$ Bundesanstalt für Materialforschung und -prüfung, Unter den Eichen 44-46, 12203 Berlin, Germany \\ ${ }^{3}$ Helmholtz-Zentrum Berlin für Materialien und Energie GmbH, Hahn-Meitner-Platz 1, 14109 Berlin, Germany
}

Correspondence: Indira S. Ritsche (indira.ritsche@mfn-berlin.de)

Received: 26 October 2017 - Revised: 22 November 2017 - Accepted: 23 November 2017 - Published: 16 January 2018

\begin{abstract}
Baleen whales (Mysticeti) are known to use low frequencies (LF; $200 \mathrm{~Hz}$ and below) and infrasound $(<20 \mathrm{~Hz})$ for communication. The lowest hearing limits of toothed whales (Odontoceti), which are able to produce ultrasound $(>20 \mathrm{kHz})$, reach low frequencies. Researchers have tried to understand the evolution of LF and infrasonic hearing in mysticetes by linking the shape of the inner ear cochlea or individual cochlear measurements to known hearing frequencies and making inferences to extinct species. Using landmark-based shape analysis of complete cochlear coiling, we show that cochlear coiling shape correlates with LF and high-frequency $(\mathrm{HF}$; $>10 \mathrm{kHz}$ ) hearing limits in cetaceans. Very LF $(\leq 50 \mathrm{~Hz})$ and infrasonic hearing are associated with, for example, a protruding second turn, a descending apex, and a high number of turns. Correlations between cochlear and cranial variables and cochlear and cranial shape indicate that low LF hearing limits are furthermore connected to longer cochleae and relatively larger cranial widths. Very LF hearing in Mysticeti appeared in the middle Miocene, and mysticete infrasonic hearing had evolved by the late Miocene. Complete cochlear coiling is suitable for estimating hearing limits in cetaceans, closely approximated by cochlear length times number of cochlear turns.
\end{abstract}

\section{Introduction}

In mammalian hearing, sound is usually transmitted by vibration of the eardrum or bone conduction into the air-filled middle ear, where it is amplified by the ossicles and further transmitted into the liquid-filled inner ear at the oval window (e.g., Fleischer, 1973). Inside the cochlea sound waves propagate towards the apex via displacement of the basilar membrane, thereby stimulating the hair cells responsible for the conduction of the acoustic signal to the nervous system. Low-frequency sound travels further up towards the apex than high-frequency sound, the latter of which is mostly detected along the basal region of the membrane, enhanced by the so-called "whispering gallery effect", due to a redistribution of wave energy toward the outer cochlear wall (Manoussaki et al., 2006, 2008). Throughout the paper we use the following definitions based on human hearing: ultrasound is above $20 \mathrm{kHz}$, the term "audible range" refers to the human audible range between $20 \mathrm{kHz}$ and $20 \mathrm{~Hz}$, frequencies of $200 \mathrm{~Hz}$ and below are called low frequencies (LF), and infrasound is below $20 \mathrm{~Hz}$ (e.g., Møller and Pedersen, 2004). In this paper, we additionally use the term "very low frequencies" for hearing frequencies of $50 \mathrm{~Hz}$ and below within the audible range. Following Heffner and Heffner (2008), frequencies above $10 \mathrm{kHz}$ are defined as high-frequency hearing.

The cetacean ear is specialized in hearing underwater (Fleischer, 1978; Nummela et al., 2004, 2007). The biggest challenge is to solve the problem of the almost identical impedance of water and of soft tissues (muscles, fat, etc.), which hampers the ability of directional hearing. Thus, the ears of aquatic mammals are acoustically isolated from the skull due to decoupling of the ear from the skull as seen in dolphins, or evolving voluminous and heavy tympanic and 
periotic bones as seen in baleen whales (Fleischer, 1978; Ketten, 1992; Nummela et al., 2004). The external auditory meatus is practically functionless in cetaceans. In odontocetes, a high-frequency waterborne sound is transmitted through the lower jaw via a fat pad to the tympanic plate and then through the ossicular chain to the oval window (Nummela et al., 2007). The sound perception pathway in mysticetes remains unknown, but several mechanisms have been presumed by different hearing models, such as the fatty sound reception pathway in minke whales (Balaenoptera acutorostrata; Yamato et al., 2012), a skull-vibration-enabled bone conduction mechanism in fin whales (Balaenoptera physalus; Cranford and Krysl, 2015), or a sound pathway via the glove finger and via the thin region of tympanic bone for lower and higher frequencies, respectively, in minke whales (Tubelli et al., 2012).

While odontocetes use ultrasound for orientation and communication, sound production data imply that mysticetes primarily use low frequencies, and it is likely that several baleen species hear well at infrasonic frequencies (Ketten, 1992, 1994; Wartzok and Ketten, 1999). There are contrasting hypotheses on the evolution of LF hearing: either dominant LF sensitivity (e.g., Fleischer, 1976a; Nummela et al., 2004; Uhen, 2004; Ekdale and Racicot, 2015; Park et al., 2017) or dominant HF sensitivity (e.g., Ketten, 1992; Fahlke et al., 2011; Churchill et al., 2016) was the ancestral state for all Neoceti (Mysticeti and Odontoceti), implying that LF and infrasonic hearing in Mysticeti is either due to retaining (and improving) the ancestral condition or due to a reduction in HF sensitivity.

A relationship between the hearing range of an animal and the properties of its cochleae might seem obvious, based on the dependence of sound propagation on cochlear anatomy (e.g., West, 1985; Vater et al., 2004). Various methods have been applied to test such a relationship, using either individual variables, and products thereof, such as number of turns and basilar membrane length (West, 1985), the ratio of the radii of the basal and apical turns (Manoussaki et al., 2008), or cochlear shape (Wannaprasert and Jeffery, 2015). However, these methods have either been used in incomparable ways, e.g., radii ratio measured from the modiolar axis (Chadwick et al., 2006; Ekdale and Racicot, 2015; Ketten et al., 2016) or using individual spiral centers for each measurement of basal and apical turn (Manoussaki et al., 2008), or they have been applied to a variety of mammals, mainly including hearing generalists (Manoussaki et al., 2008; Wannaprasert and Jeffery, 2015), not shedding much light on hearing in cetaceans in particular. Also, Ketten (1992) and Ketten et al. (2016) used basilar membrane width and thickness as correlates for LF sensitivity in whales. However, soft tissue is not preserved in fossil cochleae, and osteological features that indicate the extent of the basilar membrane, such as the secondary bony lamina, are very delicate and do not preserve well (Ekdale and Racicot, 2015).

The aim of this study is to test relationships of cochlear coiling shape with the frequency ranges presumably heard by cetaceans, and particularly to make inferences regarding the occurrence of very LF and infrasonic hearing in Mysticeti, including extinct taxa. The background for this is the theory that the snail or spiral shape of the cochlea contributes to an improved perception of low frequencies (Manoussaki et al., 2006, 2008).

\section{Materials and methods}

\subsection{Specimens}

Periotic bones used in this study include the cochleae of three extant Odontoceti, and 5 extant and 33 extinct Mysticeti. All specimens, including geochronological information, are listed in Table 1.

\subsection{Institutional abbreviations}

ChM: The Charleston Museum, Charleston, SC, USA; $\mathrm{CN}$ : Statens Naturhistoriske Museum/Zoologisk Museum, Copenhagen, Denmark; IRSNB: Institut Royal des Sciences Naturelles de Belgique, Brussels, Belgium; MB.Ma.: Museum für Naturkunde Berlin, fossil mammal collection, Berlin, Germany; NEOMED: Northeast Ohio Medical University, Rootstown, OH, USA; NMR: Natuur Museum, Rotterdam, the Netherlands; MNHN: Muséum National d'Histoire Naturelle, Paris, France; SBMB: Stiftung Bachmann-Museum Bremervörde, Germany; USNM: United States National Museum of Natural History, Washington, D.C., USA; ZMB_MAM: Museum für Naturkunde Berlin, extant mammal collection, Berlin, Germany.

\subsection{Scanning and visualization}

Cochlear parts of cetacean inner ears were micro-CTscanned using a locally developed industrial scanner at the Helmholtz-Zentrum Berlin für Materialien und Energie $\mathrm{GmbH}$, Germany (part of the CONRAD facility; Kardjilov et al., 2016). Isometric voxel length varied between $0.023 \mathrm{~mm}$ (humpback whale, Megaptera novaeangliae fetus) and $0.045 \mathrm{~mm}$ (blue whale, Balaenoptera musculus).

Reconstruction of the cochleae in three dimensions (3-D) was performed in Octopus 8 (Inside Matters), and VGStudio MAX 2.2 was used for visualization (Fig. 1a). In order to trace the basilar membrane, the primary and secondary bony laminae (Fig. 1b) were used as osteological correlates. Where the secondary bony lamina was missing, the point on the outer cochlear wall exactly opposite the primary bony lamina was used instead. The center positions between the two laminae were marked in all turns of the cochlea in 90 sections across the modiolus (Fig. $1 \mathrm{~b} ; 180^{\circ}$ in $2^{\circ}$ increments) using a function programmed in IDL 8.5. Attention was paid to capturing the complete length of the basilar membrane from the round window to the apex of the cochlea. All included specimens feature intact apices and basal turns. Marks were 
Table 1. Specimens included in the study, cochlear length, number of cochlear turns, radii ratio, and skull length. Skull length is condylobasal length measured from cranial models used by Fahlke and Hampe (2015). For family attribution and relationships, see Steeman (2007, 2010), Boessenecker and Fordyce (2015), and Marx et al. (2016).

\begin{tabular}{|c|c|c|c|c|c|c|c|c|}
\hline ID & Group/species & Family & Time & $\begin{array}{l}\text { Cochlear } \\
\text { length }(\mathrm{mm})\end{array}$ & $\begin{array}{l}\text { Number } \\
\text { of turns }\end{array}$ & $\begin{array}{l}\text { Radii } \\
\text { ratio }\end{array}$ & $\begin{array}{l}\text { Skull } \\
\text { length (mm) }\end{array}$ & $\begin{array}{l}\text { Specimen } \\
\text { number }\end{array}$ \\
\hline & ODONTOCETI & & & & & & & \\
\hline 2 & Delphinapterus leucas & Monodontidae & Recent & 47.32 & 1.9 & 4.09 & 577 & NEOMED no number \\
\hline 26 & Physeter macrocephalus & Physeteridae & Recent & 60.27 & 1.7 & 5.73 & & ZMB_MAM_45194 \\
\hline \multirow[t]{2}{*}{30} & Tursiops truncatus & Delphinidae & Recent & 34.81 & 1.7 & 4.53 & 509 & ZMB_MAM_27159 \\
\hline & MYSTICETI & & & & & & & \\
\hline 0 & Balaena mysticetus & Balaenidae & Recent & 62.78 & 2.4 & 6.24 & 2650 & CN38 \\
\hline 4 & Balaenoptera acutorostrata & Balaenopteridae & Recent & 54.35 & 2.2 & 6.65 & 1600 & NMR 9990-03410 \\
\hline 15 & Balaenoptera acutorostrata & Balaenopteridae & Recent & 55.40 & 2.2 & 6.75 & 1600 & $\mathrm{CN}$ no number \\
\hline 3 & Balaenoptera musculus & Balaenopteridae & Recent & 83.23 & 2.4 & 5.62 & 5748 & CN11x \\
\hline 13 & Megaptera novaeangliae (fetus) & Balaenopteridae & Recent & 61.37 & 2 & 6.46 & & CN14 \\
\hline 40 & Balaena primigenia & Balaenidae & Pliocene & 61.34 & 2.1 & 5.89 & & IRSNB M 887 \\
\hline 1 & Balaenidae indet. & Balaenidae & Pliocene & 57.15 & 2.2 & 5.61 & & IRSNB Vert-33312-02 \\
\hline 39 & Balaenoptera rostratella & Balaenopteridae & Pliocene & 54.14 & 2.1 & 5.12 & & IRSNB M 794 \\
\hline 6 & Eschrichtiidae indet. & Eschrichtiidae & Pliocene & 96.88 & 2.7 & 5.60 & & IRSNB Vert-33312-01 \\
\hline 25 & Herpetocetus transatlanticus & Cetotheriidae & Pliocene & 42.64 & 2.6 & 6.82 & & IRSNB Vert-33178-02 \\
\hline 17 & Aglaocetidae indet. & Aglaocetidae & late Miocene & 45.78 & 2.6 & 6.23 & & MB.Ma. 51614 \\
\hline 38 & Aglaocetus latifrons & Aglaocetidae & late Miocene & 41.75 & 2.7 & 6.70 & & IRSNB M 567 f \\
\hline 18 & Aglaocetus sp. & Aglaocetidae & late Miocene & 41.91 & 2.7 & 6.55 & & MB.Ma. 51615 \\
\hline 16 & Aglaocetus patulus & Aglaocetidae & late Miocene & 44.10 & 2.8 & 6.06 & 1601 & MB.Ma. 51613 \\
\hline 24 & Aglaocetus patulus & Aglaocetidae & late Miocene & 41.98 & 2.7 & 6.14 & 1601 & MB.Ma. 51622 \\
\hline 10 & Amphicetus later & Diorocetidae & late Miocene & 44.35 & 2.7 & 6.98 & & IRSNB M 622 \\
\hline 35 & Amphicetus later & Diorocetidae & late Miocene & 47.26 & 2.4 & 4.91 & & IRSNB M 575 \\
\hline 19 & Diorocetidae indet. & Diorocetidae & late Miocene & 42.83 & 2.7 & 6.17 & & MB.Ma. 51616 \\
\hline 20 & Diorocetidae indet. & Diorocetidae & late Miocene & 48.66 & 2.7 & 6.74 & & MB.Ma. 51618 \\
\hline 21 & Diorocetidae indet. & Diorocetidae & late Miocene & 50.13 & 3 & 6.04 & & MB.Ma. 51619 \\
\hline 23 & Diorocetidae indet. & Diorocetidae & late Miocene & 49.06 & 2.8 & 6.59 & & MB.Ma. 51621 \\
\hline 37 & Diorocetidae indet. & Diorocetidae & late Miocene & 45.74 & 2.7 & 6.04 & & MB.Ma. 51623 \\
\hline 22 & Diorocetus sp. & Diorocetidae & late Miocene & 47.21 & 2.8 & 6.56 & & MB.Ma. 51620 \\
\hline 31 & Megaptera miocaena & Balaenopteridae & late Miocene & 55.40 & 2.6 & 7.30 & & USNM 10300 \\
\hline 12 & Megapteropsis robusta & Balaenopteridae & late Miocene & 82.23 & 2.6 & 6.46 & & IRSNB M 809 a \\
\hline 9 & Parietobalaena affinis & Pelocetidae & late Miocene & 41.27 & 2.5 & 6.68 & & IRSNB M 605 b \\
\hline 27 & Piscobalaena nana & Cetotheriidae & late Miocene & 45.07 & 2.6 & 6.35 & 1064 & MNHN PPI259 \\
\hline 29 & Piscobalaena nana & Cetotheriidae & late Miocene & 43.15 & 2.5 & 6.07 & 1064 & MNHN SAS 892 \\
\hline 11 & Aglaocetus burtinii & Aglaocetidae & middle Miocene & 43.21 & 2.4 & 5.87 & & IRSNB M 676 \\
\hline 33 & Diorocetus hiatus & Diorocetidae & middle Miocene & 42.03 & 2.7 & 6.34 & & USNM 23494 \\
\hline 5 & Diorocetus sp. "type Freetz" & Diorocetidae & middle Miocene & 45.54 & 2.5 & 6.20 & & SBMB A2008:1252 \\
\hline 34 & Halicetus ignotus & Pelocetidae & middle Miocene & 55.35 & 2.3 & 6.11 & & USNM 23636 \\
\hline 7 & Heterocetus sprangii & Diorocetidae & middle Miocene & 48.36 & 2.8 & 6.88 & & SBMB A2008:1253 \\
\hline 32 & Parietobalaena palmeri & Pelocetidae & middle Miocene & 41.17 & 2.5 & 7.44 & 1014 & USNM 13874 \\
\hline 8 & Amphicetus later & Diorocetidae & early to middle Miocene & 46.69 & 2 & 4.56 & & IRSNB M 548 a \\
\hline 28 & Eomysticetus whitmorei & Eomysticetidae & late Oligocene & 36.44 & 2.4 & 7.06 & & ChM PV4253 \\
\hline 14 & Micromysticetus rothauseni & Eomysticetidae & late Oligocene & 37.69 & 2.5 & 7.45 & & ChM PV7225 \\
\hline 36 & toothed mysticete & & Oligocene & 35.97 & 2.1 & 6.37 & & ChM PV5720 \\
\hline
\end{tabular}

connected to form a continuous line and exported as volume data (image stacks).

\subsection{Number of turns and radii ratio}

The number of cochlear turns was determined at a precision of $2^{\circ}$ based on the images used to trace the bony laminae.

The ratio of the most basal and the most apical cochlear turns was determined according to the method as introduced by Manoussaki et al. (2008), allowing both turns to have one centrum each, as opposed to a common centrum on the modiolar axis (cf. Chadwick et al., 2006; Ekdale and Racicot, 2015; Ketten et al., 2016). For the determi- nation of the radii of curvature of these turns the line representative of the basilar membrane (derived as described above) was projected in apical view onto an isometric twodimensional (2-D) grid created with MatheKonstruktor (http: //www.martware.de/mathekonstruktor.html, last accessed 14 April 2016). Circles were fitted onto the basal and apical turns in such a way that lines were parallel with the most basal and most apical $90^{\circ}$ of the respective turn (Fig. 1c). Radii and the ratio between the radii of the basal turn of the cochlea and the apical turn were then calculated in Microsoft Excel 2010 based on the 2-D coordinates of three points on the most basal and most apical quarter turns. 

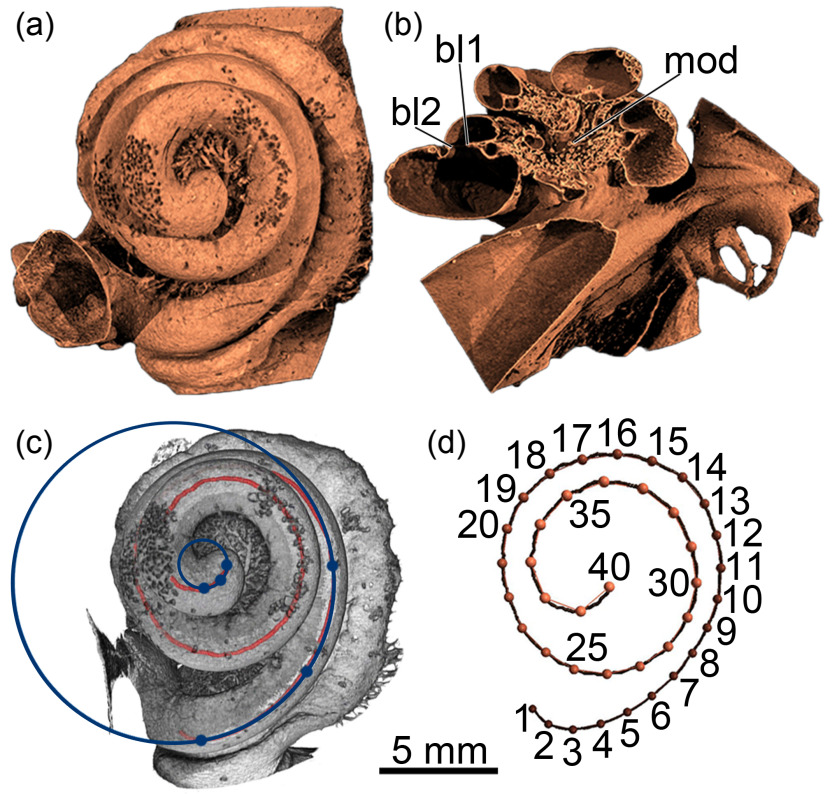

Figure 1. Cochlear anatomy and visualization of methods. (a) Three-dimensional rendering of the cochlea (shown as right) of $\mathrm{Bal}$ aenoptera acutorostrata in apical view. (b) Same, virtually transected along the modiolus (mod) showing the primary and secondary bony laminae (bl1 and bl2, respectively). (c) Radii ratio method as applied in this study: circles superimposed onto basal and apical turns of a 2-D projection of the path tracing the basilar membrane within the cochlea. Dots represent three points on each circle for calculation of the respective radius. (d) Landmark-based geometric morphometrics: 3-D resampled path with landmarks 1 to 40.

\subsection{Cochlear length and geometric morphometrics}

Exported image stacks of the CT scans were read into ZIBAmira 2015.24, where automatic threshold selection was performed. Selection growth was applied twice, and the segmented material was extracted as a thin, tube-shaped coil, representing the position of the basilar membrane throughout the cochlea. Three-dimensional surfaces were saved in .stl file format. Surfaces of left cochleae were flipped using MeshLab v.1.3.1 (http://meshlab.sourceforge.net/) so that all landmark configurations would later represent the coiling of cochleae of the same (right) body side. Files were imported into TIVMI V2.1, where paths were fitted to the surface using an arbitrary adequate number of points, again paying special attention to including basal and apical ends of the coil. Paths were then resampled to be represented by 40 equally spaced semi-landmarks (Fig. 1d). Resampled path length was used as an estimate of cochlear length in this study.

Geometric morphometrics is a landmark-based approach to shape analysis. Comprehensive reviews of the method are given by Mitteroecker and Gunz (2009), Zelditch et al. (2012), and Adams et al. (2013). Usually, homologous landmarks are collected on all objects that are included in the analysis. Outlines or curves with homologous start and end points in each object are also frequently used, and the same arbitrary number of equally spaced semi-landmarks is placed along that feature in each object. Landmark configurations are superimposed by minimizing the sum of squared distances between corresponding landmarks from all objects to the average configuration (Procrustes superimposition), removing size, position, and orientation of the objects, and leaving only shape information. Centroid size is the square root of the sum of the squared distances of the landmarks from the centroid and represents the size of a landmark configuration.

In our study, the coordinates of 40 semi-landmarks along the length of the cochlea (Fig. 1d) were exported as text files. After assembling semi-landmark coordinates of all 41 specimens in Microsoft Excel 2010, a single matrix was exported as a .txt file and read into MorphoJ 1.06e (Klingenberg, 2011), where Procrustes superimposition was performed.

\subsection{Sources and definition of hearing limits}

To date, no hearing measurements have been taken on baleen whales or on sperm whales (Physeter macrocephalus), and so the current knowledge of their hearing abilities is based on their vocalization frequencies only. The hearing data are thus indirect or deduced. It is generally accepted that most animals are able to hear the frequencies they produce. The odontocetes Delphinapterus leucas (beluga whale) and Tursiops truncatus (common bottlenose dolphin) are good examples to support this approach, as known vocalization limits are almost equal to known hearing limits (e.g., Johnson, 1966; Awbrey et al., 1988; Herzing, 2000; Karlsen et al., 2002; Blomqvist and Amundin, 2004; Castellote et al., 2014; Mishima et al., 2015). Hearing data were used whenever possible, and vocalization data when no hearing data were available. For comparability, highest and lowest vocalization frequencies were used as proxies for HF and LF hearing limits, respectively. Sources of LF and HF hearing limits are indicated in Table 2. For easier reading, regardless of the source used, we use the terms "LF hearing" and "HF hearing" below.

\subsection{Statistical analysis}

Principal components analysis (PCA) of the shape coordinates was performed in MorphoJ. In order to test dependence of cochlear coiling shape on centroid size, additional linear regression of shape coordinates on log centroid size was performed in MorphoJ.

PC scores were correlated with cochlear length, number of cochlear turns, radii ratio, and skull length (Table 1), as well as LF and HF hearing limits (Table 2). Skull length was used here as a proxy of both intermeatal distance (used for correlations by Wannaprasert and Jeffery, 2015) and body size. Skull lengths are condylo-basal lengths measured by 
Table 2. Reported hearing and vocalization limits for extant species included in this study.

\begin{tabular}{llllll}
\hline Species & Suborder & $\begin{array}{l}\text { Low-frequency } \\
\text { limit in Hz }\end{array}$ & $\begin{array}{l}\text { High-frequency } \\
\text { limit in kHz }\end{array}$ & $\begin{array}{l}\text { Results based } \\
\text { on }\end{array}$ & Reference \\
\hline $\begin{array}{l}\text { Tursiops } \\
\text { truncatus }\end{array}$ & Odontoceti & $150-200$ & 150 & Hearing tests & $\begin{array}{l}\text { Johnson (1966), } \\
\text { Turl (1993) }\end{array}$ \\
\hline $\begin{array}{l}\text { Delphinapterus } \\
\text { leucas }\end{array}$ & Odontoceti & 125 & 150 & Hearing tests & $\begin{array}{l}\text { Awbrey et al. (1988), } \\
\text { Castellote et al. (2014) }\end{array}$ \\
\hline $\begin{array}{l}\text { Physeter } \\
\text { macrocephalus }\end{array}$ & Odontoceti & 200 & 32 & Vocalization & $\begin{array}{l}\text { Backus and Schevill } \\
\text { (1966), Madsen et al. } \\
\text { (2002) }\end{array}$ \\
\hline $\begin{array}{l}\text { Balaenoptera } \\
\text { acutorostrata }\end{array}$ & Mysticeti & 50 & 20 & Vocalization & $\begin{array}{l}\text { Gedamke et al. (2001), } \\
\text { Erbe (2002) }\end{array}$ \\
\hline $\begin{array}{l}\text { Balaenoptera } \\
\text { musculus }\end{array}$ & Mysticeti & 9 & 8 & Vocalization & $\begin{array}{l}\text { Beamish and Mitchell } \\
\text { (1971), Mellinger and } \\
\text { Clark (2003) }\end{array}$ \\
\hline $\begin{array}{l}\text { Megaptera } \\
\text { novaeangliae }\end{array}$ & Mysticeti & 20 & & Vocalization & $\begin{array}{l}\text { Thompson et al. (1986), } \\
\text { Erbe (2002) }\end{array}$ \\
\hline $\begin{array}{l}\text { Balaena } \\
\text { mysticetus }\end{array}$ & Mysticeti & $20-25$ & 54 & Vocalization & $\begin{array}{l}\text { Cummings and Holli- } \\
\text { day (1987), Erbe (2002) }\end{array}$ \\
\hline
\end{tabular}

JMF on cranial 3-D models of adult individuals of the same species used in Fahlke and Hampe (2015). Sources of LF and HF hearing limits are indicated in Table 2. All variables except the PC scores were $\log 10$-transformed prior to correlation. All correlations and regressions were done in Past 3.11 (Hammer et al., 2001). Pearson correlation and linear regression were used. Statistical significance was accepted at $P<0.05$.

Specimen CN14 is from a fetus of Megaptera novaeangliae and was excluded from correlations involving skull length and implied hearing frequencies, because these measurements are known for adult individuals only.

We also used the same PC scores derived from the PCA including all 41 specimens for correlation with hearing limits and skull length that were only available for seven and eleven specimens, respectively. No individual PCA was performed for these specimens, because that would have lowered statistical reliability.

Additionally, we examined relationships between cochlear coiling and cranial shape. For eight of the included species cranial shape data were available from Fahlke and Hampe (2015), including both the symmetric and asymmetry component of shape. These species are Tursiops truncatus, Delphinapterus leucas, Balaenoptera acutorostrata, Balaenoptera musculus, Megaptera novaeangliae, Balaena mysticetus, Piscobalaena nana, and Parietobalaena palmeri. These species were represented by 20 specimens with cranial shape data (Fahlke and Hampe, 2015) and by 10 specimens with cochlear shape data in the present study. Due to these differing numbers of available specimens, shape infor- mation was averaged by species, and individual Procrustes fits and PCAs for these samples needed to be performed. Again, cranial shape information of $M$. novaeangliae was that of an adult specimen while the cochlea analyzed here is that of a fetus. Therefore, only nine cochlear specimens and 18 cranial specimens (representing seven species: two odontocetes, three extant mysticetes, and two extinct mysticetes) were used for correlation of cranial and cochlear shape data.

\section{Results}

\subsection{PCA}

PCA (Fig. 2) of cochlear coiling shape shows a clear distinction between Odontoceti and Mysticeti when plotting PC1 (representing $69.66 \%$ of total variance in the data) against PC2 $(16.30 \%)$.

Shape changes along the PCs involve complete cochlear coiling (Fig. 2). High values on PC1 are associated with very regular cochlear coiling, with the basilar membrane steadily ascending until completion of the second turn. The basal turn is wide and ascends slightly at its arched basal end at the fenestra cochleae. The apical end is parallel to the second turn, and number of turns only slightly exceeds two. Low values on PC1 are associated with compact coiling, with a less steadily ascending membrane (horizontal turns connected by steep ascents). The most basal end lies below the level of the basal turn. The second turn protrudes over the basal turn, and the apex descends at the top. The coil is high in the apical direction, and number of turns is 2.5 or above. On PC2, 


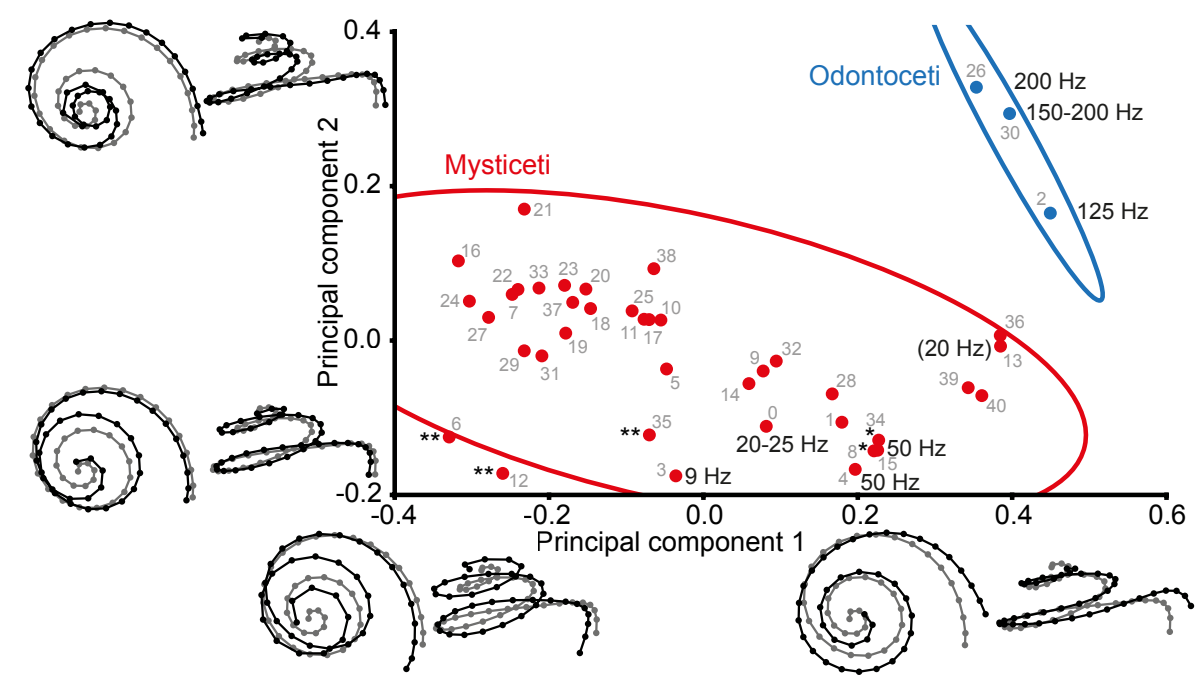

Figure 2. PCA plot of shape variation of cochlear coiling. Lines represent $95 \%$ confidence ellipses for Mysticeti (red) and Odontoceti (blue). Shape change along the axes is shown as black landmark configurations against the average shape (in gray) in apical view and in profile. Known lowest hearing limits in $\mathrm{Hz}$ are given for extant cetaceans (see Table 2). Number in parentheses refers to a fetus. $*$ denotes extinct mysticetes with presumed very low frequency hearing $(50 \mathrm{~Hz}$ and below $)$ ** denotes extinct mysticetes with presumed infrasonic hearing (below $20 \mathrm{~Hz}$ ). Gray numbers represent identification numbers (ID) listed in Table 2 . The specimens plotting outside of the ellipse are Megapteropsis robusta (ID12) and Eschrichtiidae indet. (ID6).

higher values are associated with a wide basal turn and a very narrow second turn. Low values are again associated with a wide, almost-protruding second turn and a descending apex. At high values on PC3 (5.46\% of total variance; not included in Fig. 2) the basal turn is quite wide, and the second and apical turns ascend steadily, while lower values on PC3 appear to be connected with a narrower basal turn, tilting of the second turn, and deflection of the apex.

Only $12.69 \%$ of the variation in the data is dependent on size, as regression of shape coordinates on logarithmic centroid size revealed (permutation test against null hypothesis of independence: $P=0.007)$. Therefore cochlear size is not the main cause of shape differences.

\subsection{Distribution of LF hearing limits in the PCA plot}

LF hearing limits between 200 and $125 \mathrm{~Hz}$ (low frequencies within the human audible range; Møller and Pedersen, 2004) are found in extant Odontoceti on positive values along both axes in the upper right quadrant of the PCA plot (Fig. 2). Very low-frequency hearing of $50 \mathrm{~Hz}$ and below is found in the lower right quadrant at positive values on $\mathrm{PC} 1$ and negative values on PC2 (Balaenoptera acutorostrata and Balaena mysticetus). The only extant mysticete in the study that is presumably capable of true infrasonic hearing, Balaenoptera musculus (cf. Mellinger and Clark, 2003), plots in the lower left quadrant at negative values on both axes.

\subsection{Relations of cochlear coiling shape, cochlear metrics, hearing frequencies, and cranial shape}

The original PC1, PC2, and PC3 of cochlear coiling shape, as well as cochlear length, number of cochlear turns, radii ratio, and skull length, were used.

Based on these individual variables, 17 significant correlations were found (Table 3, upper three sections, normal font). Linear regressions for all significant correlations that involve PC1 and PC2 of cochlear coiling shape of the original PCA are shown in Fig. 3a-g. Our results indicate that cetacean cochlear coiling, cochlear metrics, and hearing frequencies are linked as follows: higher values on PC1 are associated with lower numbers of cochlear turns (Fig. 3a), a lower radii ratio (Fig. 3b), and both higher LF and HF hearing limits (Fig. 3e, g). Higher values on PC2 are associated with shorter cochlear lengths (Fig. 3c), with smaller skull length (Fig. 3d), and again with higher LF hearing limits (Fig. 3f). Higher values on PC3 are related to shorter cochlear lengths and higher radii ratios. It should be added that, while number of cochlear turns and cochlear length each relate to individual PCs (PC1, and PCs 2 and 3, respectively), the product of both these variables strongly correlates with all three PCs of cochlear coiling shape (Table 3, upper section, in italics).

Lower LF hearing limits furthermore occur at longer cochlear lengths, higher numbers of cochlear turns, and together with lower HF hearing limits. Lower HF hearing limits also occur at longer cochlear lengths and higher numbers of cochlear turns, and are also connected to a larger radii ratio (Table 3, third section, normal lettering). Not surpris- 
Table 3. Significant correlations (Pearson) found in this study. * means separate Procrustes fit and PCA for cochlear specimens with available cranial shape data. For correlation of cochlear and cranial shape, shape data were averaged by species prior to PCA.

\begin{tabular}{|c|c|c|c|}
\hline Significant correlation & Sample & $r$ & $P$ \\
\hline PC1 $-\log 10$ number of turns & $n=41$ & -0.8932 & $<0.0001$ \\
\hline $\mathrm{PC} 1-\log 10$ radii ratio & & -0.3731 & 0.0163 \\
\hline$P C 1-\log 10$ (cochlear length $\times$ number of turns) & & -0.5228 & 0.0005 \\
\hline PC $2-\log 10$ cochlear length & & -0.4316 & 0.0048 \\
\hline PC2 $-\log 10$ (cochlear length $\times$ number of turns $)$ & & -0.4337 & 0.0046 \\
\hline PC $3-\log 10$ cochlear length & & -0.5163 & 0.0006 \\
\hline $\mathrm{PC} 3-\log 10$ radii ratio & & 0.3959 & 0.0104 \\
\hline PC3 - $\log 10$ (cochlear length $\times$ number of turns) & & -0.3573 & 0.0218 \\
\hline $\log 10$ number of turns $-\log 10$ radii ratio & & 0.5668 & 0.0001 \\
\hline PC2 $-\log 10$ skull length & $n=11(41)$ & -0.7800 & 0.0046 \\
\hline Log10 skull length $-\log 10$ cochlear length & & 0.8626 & 0.0006 \\
\hline Log10 lf limit - PC1 & $n=7(41)$ & 0.9585 & 0.0007 \\
\hline $\log 10$ lf limit $-\mathrm{PC} 2$ & & 0.8685 & 0.0112 \\
\hline Log 10 lf limit $-\log 10$ cochlear length & & -0.7841 & 0.0369 \\
\hline $\log 10$ lf limit $-\log 10$ number of turns & & -0.9467 & 0.0012 \\
\hline Log10 If limit $-\log 10$ (cochlear length $\times$ number of turns) & & -0.9108 & 0.0044 \\
\hline $\log 10$ lf limit $-\log 10 \mathrm{hf}$ limit & & 0.8389 & 0.0183 \\
\hline Log 10 hf limit - PC1 & & 0.9143 & 0.0040 \\
\hline Log $10 \mathrm{hf}$ limit $-\log 10$ cochlear length & & -0.8289 & 0.0212 \\
\hline $\log 10 \mathrm{hf}$ limit $-\log 10$ number of turns & & -0.8276 & 0.0215 \\
\hline $\log 10 \mathrm{hf} \operatorname{limit}-\log 10$ radii ratio & & -0.7877 & 0.0354 \\
\hline Log10 hf limit - log10 (cochlear length $\times$ number of turns) & & -0.8955 & 0.0064 \\
\hline PC1 - symmetric cranial shape PC1 & cochlear shape: $n=9^{*}$ & 0.7773 & 0.0397 \\
\hline PC1 - asymmetric cranial shape PC1 & cranial shape: $n=18$ & -0.7978 & 0.0316 \\
\hline Log 10 lf limit - symmetric cranial shape PC3 & (7 species) & 0.6089 & 0.0073 \\
\hline Log10 hf limit - asymmetric cranial shape PC1 & & -0.7104 & 0.0010 \\
\hline
\end{tabular}

ingly, cochlear length times number of cochlear turns correlates with both LF and HF hearing limits (Table 3, third section, in italics). Additionally, but less importantly for this study, a higher number of cochlear turns is associated with a larger radii ratio, and a longer skull is associated with longer cochlear length (Table 3, upper two sections).

In an additional analysis, PC1 (81.54\% of total variation) and PC2 $(12.54 \%)$ of cochlear coiling shape derived from additional PCA of seven species - as well as PC1 $(55.74 \%)$, PC2 $(28.01 \%)$, PC3 $(6.84 \%)$, and PC4 $(6.21 \%)$ of the symmetric component of cranial shape and PC1 $(49.63 \%), \mathrm{PC} 2$ $(22.65 \%)$, PC3 $(15.68 \%)$, and PC4 (7.95\%) of the asymmetry component of cranial shape - were used in order to detect links between cochlear and cranial shape. The PC axes of cochlear coiling shape of seven species span very similar shape differences to those of the original PCA (see Fig. 2), and the PC axes of the symmetric and asymmetry components of cranial shape are comparable to those described by Fahlke and Hampe (2015). Four significant correlations were found (Table 3, lower section): higher values on PC1 of cochlear coiling are linked to higher values on PC1 of symmetric shape (i.e., shorter nasals that are strongly shifted posteriorly; so-called "telescoping"; Miller, 1923) and to lower values on PC1 of asymmetry (i.e., a larger right side of the cranium).

Furthermore, a lower LF limit is related to smaller values on PC3 of symmetric shape change (i.e., a broader posterior part of the cranium). HF hearing limits become higher with lower values on PC1 of asymmetry (i.e., with a larger right side of the cranium).

\section{Discussion}

\subsection{Interpretation of the correlations}

A strong negative correlation between PC1 of cochlear coiling shape and number of turns is not surprising, as it is fairly obvious that number of turns is the major factor influencing the shape of a coil. This connection was previously documented by Wannaprasert and Jeffery (2015). PC1, as well as number of turns, is associated with both HF and LF hearing limits, which in turn are linked to each other, i.e., represent the inferred hearing range rather than individual limits. A strong connection between cochlear coiling shape and hearing range has not been reported previ- 

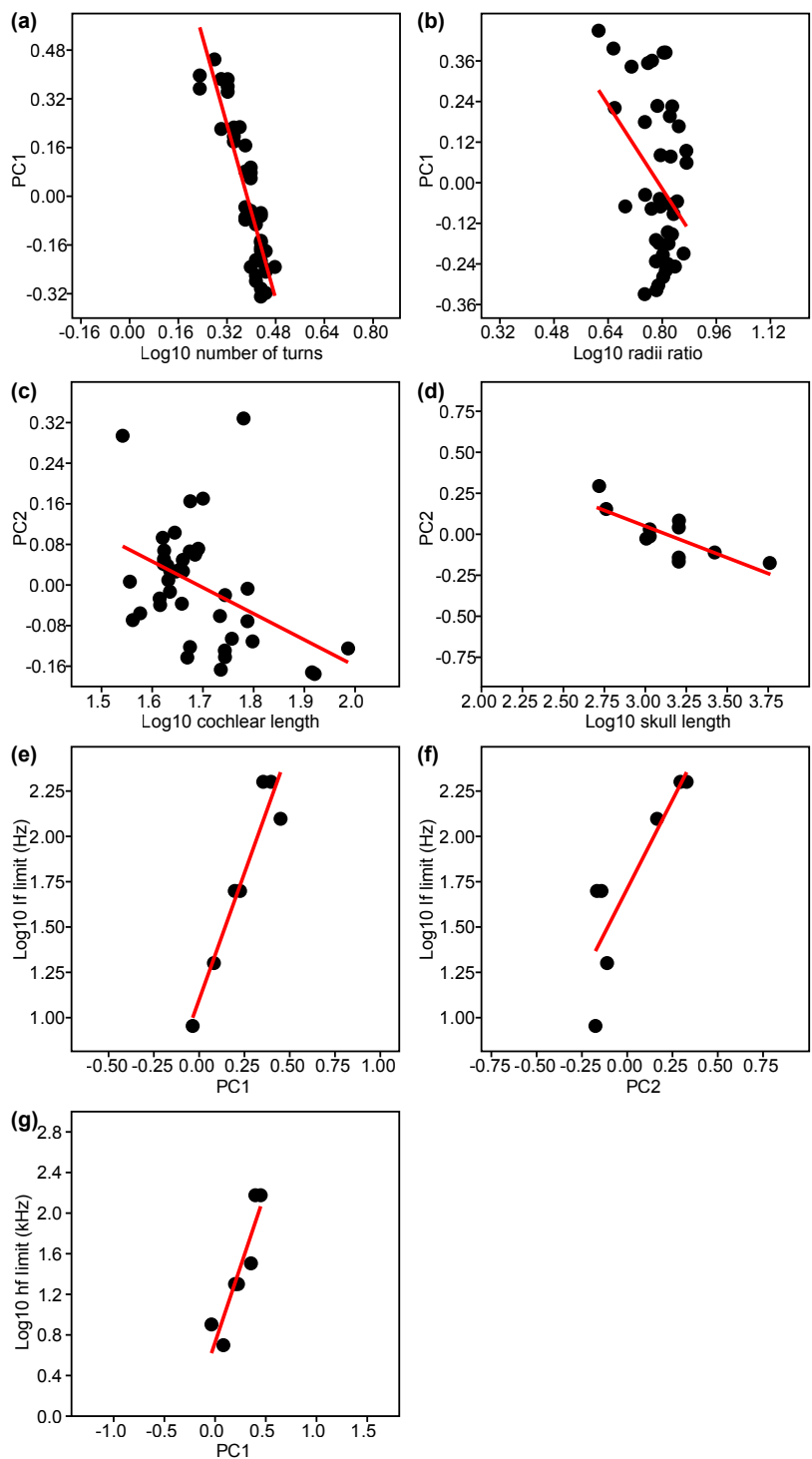

Figure 3. (a-g) Linear regressions for significant correlations of PC1 and PC2 with individual variables tested in this study.

ously, as Wannaprasert and Jeffery (2015) were not able to link the PCs with the highest variance to hearing frequencies but reported a positive correlation with PC4 (only $7.2 \%$ of variance in their study). Also, Ekdale (2016) did not find a link between cochlear coiling shape and hearing abilities using PCA. Number of cochlear turns, deemed functionally insignificant by Fleischer (1976a), was already identified as an indicator for LF hearing sensitivity by West (1985).

Interestingly, radii ratio has previously only been linked to LF hearing limits or thresholds in hearing generalists (Chadwick et al., 2006; Manoussaki et al., 2008) and LF specialists (Ketten et al., 2016). In this study; however, radii ratio is connected to PC1, number of turns, and HF hearing limit. Thus, there is only an indirect connection of radii ratio and
LF hearing via the coupling of the hearing limits. Correlations of PC1 and number of turns with each other and both hearing limits are stronger (lower $P$ value, higher absolute values of $r$; Table 3) than any correlations of radii ratio.

Shape change along PC2 is linked to cochlear length, which in turn increases with skull length. Longer cochlear and skull lengths are connected with lower frequency ranges. Notably, this link seems to be unrelated to the number of cochlear turns, as number of turns correlated neither with cochlear length nor with skull length. In cetaceans, a connection between cochlear length, skull size, and, consequently, animal size was detected, although no significant correlation between cochlear length and frequency was found by Ketten (1992). Wannaprasert and Jeffery (2015) found correlations between cochlear length, skull size, and also LF hearing limit, but they used intermeatal distance instead of skull length as a proxy for body size. Relative intermeatal distance is reflected in PC 3 of symmetric cranial shape change in this present study, and our results support the link between low LF hearing limits and relatively broader posterior portions of the cranium. The correlations of PC3 of cochlear shape change with cochlear length (negative) and radii ratio (positive) must be regarded carefully. PC 3 only covers $5.46 \%$ of total variation in the data. Thus, the shape changes along PC3 outlined in the results section are hardly recognizable in individual specimens and are probably obliterated by the more dominant shape changes along the PCs that represent more variation.

All three significant PCs as well as both hearing limits have significant correlations with cochlear length times number of turns. The relationship between this product and LF hearing limits has already been postulated by West (1985), Manoussaki et al. (2008), and Wannaprasert and Jeffery (2015). Since number of turns is already a defining factor of cochlear coiling shape, and cochlear length at least correlates with PC2, it is not surprising that the product of both serves well to approximate overall cochlear coiling shape.

Our findings regarding cetacean cochlear coiling indicate that (1) cochlear coiling shape may be used to infer hearing range; (2) radii ratio might serve as a proxy for cochlear coiling shape and HF hearing limit, but not LF hearing limit; (3) number of turns is a stronger proxy for cochlear coiling shape and should be preferred over radii ratio; and (4) the closest representation of cochlear coiling shape and strong correlations with both LF and HF hearing limits are achieved when cochlear length times number of turns is used.

The correlation between hearing limits and cranial shape links the symmetric, broad mysticete cranial shape to lower hearing frequencies and the asymmetric, "telescoped" odontocete cranial shape to higher hearing frequencies, and thus quantitatively supports the widely accepted assumption of this interrelation (cf. Fleischer, 1976b). Consequently, the shape of cochlear coiling that is linked to hearing frequencies also links to cranial shape. 


\subsection{Occurrence of very low-frequency and infrasonic hearing}

Based on cochlear coiling shape, a middle Miocene diorocetid Amphicetus later (IRSNB M 548a, formerly Mesocetus longirostris, Steeman, 2010) and the middle Miocene Halicetus ignotus (both denoted * in Fig. 2, left to right) are found close to B. acutorostrata (ID4, ID15), in the lower right quadrant of the PCA plot, implying that very lowfrequency hearing of around $50 \mathrm{~Hz}$ had already evolved by the middle Miocene. The Oligocene eomysticetids Eomysticetus whitmorei (ID28) and Micromysticetus rothauseni (ID14) also plot in the vicinity, but higher on PC2, suggesting the possibility that even the late Oligocene Chaeomysticeti were capable of hearing frequencies between 100 and $50 \mathrm{~Hz}$. A Pliocene eschrichtiid, a late Miocene balaenopterid (Megapteropsis robusta), and the late Miocene Amphicetus later (IRSNB M 575; all three denoted ** in Fig. 2, left to right) plot beyond B. musculus (ID3) in the lower left quadrant. This position suggests that infrasonic hearing below $20 \mathrm{~Hz}$ had evolved by the late Miocene. The extraordinary position of $M$. robusta and of a Pliocene member of Eschrichtiidae outside the confidence ellipse of mysticetes indicates a unique cochlear coiling shape and leads to the assumption that these two extinct balaenopteroids were probably specialized to very low and infrasonic frequencies only.

The upper left quadrant with negative values on PC1 and positive values on PC2 is occupied by middle Miocene to Pliocene mysticetes. The lack of extant cetaceans in this plot area prohibits direct inference of a LF hearing limit, but the distribution of cetaceans with reported hearing and vocalization limits (see Table 2) suggests that all these extinct mysticetes were also capable of hearing frequencies of $125 \mathrm{~Hz}$ and below.

The three specimens of Amphicetus later (revised by Steeman, 2010) occupy different quadrants of the graph and are positioned far apart from each other. A. later (IRSNB M 622, formerly Heterocetus sprangii) plots in the upper right quadrant, whereas A. later (IRSNB M 548a, formerly Mesocetus longirostris) and Amphicetus later (IRSNB M 575) plot in the lower right and lower left quadrant, respectively. Intraspecific variation does not seem to have a strong influence on the positions of individuals in the plot, as seen in $\mathrm{B}$. acutorostrata. Therefore, the scattering of individuals of $A$. later across the plot might imply that these individuals actually represent different species, and are not conspecific, as Steeman (2010) suggested.

The number of $20 \mathrm{~Hz}$ in parentheses in the upper right quadrant of the graph refers to Megaptera novaeangliae, a fetus of unknown developmental stage and the only fetal individual included in this study. The LF vocalization limit of $20 \mathrm{~Hz}$ has been reported for adult individuals (see Table 2). However, all adult mysticetes with presumed very LF and infrasonic hearing are found at lower values on PC2. The position of the fetus of $M$. novaeangliae is shifted towards the higher LF limit of the odontocetes, plotting next to an Oligocene toothed mysticete (ID36), which obviously points to a deviating hearing ability of the unborn because of the yet incomplete development of the cochlear coiling shape. It cannot be ruled out that phylogenetic relationships potentially play a role in the patterns observed in Fig. 2. Nevertheless, we decided not to perform a phylogenetic analysis, because several specimens included here, especially those from the Neogene of Belgium and Germany, are described on isolated periotic bones only. Phylogenetic relationships for part of the taxa are either not resolved or currently under debate (see Steeman, 2007; Hampe and Ritsche, 2011; Boessenecker and Fordyce, 2015; Marx and Fordyce, 2015).

In conclusion, it should be noted that, although we consider it likely that low and even very low frequencies were heard by the earliest mysticetes, our results do not indicate the occurrence of infrasonic hearing before the late Miocene. An early sensitivity for low frequencies is in concordance with the results by Nummela et al. (2004) and Uhen (2004), who analyzed the anatomy of archaeocete outer, middle, and inner ears. Infrasonic hearing is a specialization that possibly evolved several times within baleen whales, as its occurrence in Diorocetidae, Eschrichtiidae, and Balaenopteridae implies. Therefore, within cetaceans, infrasonic hearing can be regarded as a purely mysticete trait, and ultrasonic hearing as an odontocete trait. Also, Mourlam and Orliac (2017) concluded that infrasonic and ultrasonic hearing evolved after the emergence of fully aquatic whales and within Neoceti, which contrasts with previous results of infrasonic sensitivity in basilosaurids (Ekdale, 2016; Park et al., 2017). However, no archaeocetes were included in our study, and a more detailed interpretation would be merely speculative based on our data.

\subsection{Method applicability and comparisons}

We used hearing thresholds determined by experiment where possible (Table 2). However, as mentioned above, actual frequency thresholds were only available for the two smaller odontocetes, Tursiops truncatus and Delphinapterus leucas. For Physeter and the extant mysticetes included, such experiments have not been conducted as of yet (at least not for adult individuals). Therefore, highest and lowest vocalization frequencies observed in the wild were used as proxies for hearing frequencies (Table 2). We are aware that the lack of hearing data for mysticetes and adult sperm whales is critical, as is the combination of hearing and vocalization frequencies in correlations.

Furthermore, observations of vocalization frequencies as well as experimentally determined hearing thresholds need to be considered carefully. For example, the highest observed frequency emitted by a blue whale is thought to be $8 \mathrm{kHz}$, but a noise at $31 \mathrm{kHz}$ was also recorded around a blue whale, however, it might have been emitted by a different animal (Beamish and Mitchell, 1971). 
Experimental hearing tests are also problematic, because they often refer to the response of a tested subject at certain frequencies, a circumstance that, in itself, is a source of uncertainty. For reasons of comparability, hearing tests are often conducted at a sound pressure level of $60 \mathrm{~dB}$ re $20 \mu \mathrm{Pa}$ in air and at $120 \mathrm{~dB}$ re $1 \mu \mathrm{Pa}$ in water as an equivalent sound pressure level (West, 1985; Wartzok and Ketten, 1999). Other studies, such as that by Wannaprasert and Jeffery (2015), used frequency limits that had been determined, for example, at $140 \mathrm{~dB}$ re $1 \mu \mathrm{Pa}$ with the sound source positioned directly in front of the single subject (in this case Delphinapterus leucas; Johnson et al., 1989, which is the same reference indirectly used by Wannaprasert and Jeffery, 2015, who cited Nedwell et al., 2004). It is hard to tell whether the LF response by the subject at such high sound pressure levels is due to hearing or rather feeling the sound wave (see Turl, 1993). The hearing test for belugas referred to in this study was conducted at a maximum sound pressure level of $120 \mathrm{~dB}$ re $1 \mu \mathrm{Pa}$ and with three captive individuals (Awbrey et al., 1988).

Taken together, LF and HF hearing limits, as used here, can only be approximations of the actual lowest and highest frequencies these cetaceans are able to hear or vocalize, and that correlations with these hearing limits indicate but do not prove that certain characteristics are responsible for LF and infrasonic hearing abilities. Additionally, HF and LF hearing and vocalization limits were only available for seven species included in our study. Of these species, Megaptera novaeangliae was represented by a fetus and was therefore excluded, but Balaenoptera acutorostrata was represented by two adult specimens, leaving us at a sample size of $n=7$ (out of 41). Based on this small sample size, statistical significance of the correlations of PC scores with LF and HF hearing limits needs to be regarded carefully, and certainly the inclusion of more extant cetaceans with known hearing limits and vocalization spectra would be worthwhile in order to corroborate our results in the future.

In this study, we demonstrated that cochlear coiling shape is related to LF and HF hearing limits in cetaceans. We also found that number of turns and especially cochlear length times number of turns (see West, 1985) offer reliable and more readily measurable alternatives in order to estimate hearing ranges. However, overall cochlear coiling shape includes cochlear characters that cochlear length or number of turns do not cover, for example, the protrusion of the second cochlear turn over the basal turn, the position of the basal end below the level of the basal turn, or the descending apex characters that are all related to very LF and infrasonic hearing.

Of course, there are other cochlear measurements (e.g., cochlear height, and other products and ratios of measurements, e.g., basal ratio, axial pitch, or cochlear slope) that surely have functional significance (Ekdale and Racicot, 2015). However, we did not use them here, because, like cochlear length times number of turns, they do not cover all aspects of cochlear coiling shape. Thus, their inclusion would not have added to this study but rather would have reduced the clarity of the discussion.

Like other individual measurements, the radii ratio method does not yield comprehensive information on cochlear coiling shape. While the relationship between the curvature of the most basal and the most apical turns gives us some information regarding wave energy redistribution and consequently propagation of LF waves and reception of LF sound (Manoussaki et al., 2006, 2008), the length, number of turns, and shape of the turns in between the basal and apical turn are not covered by this method.

Furthermore, there is a widely ignored problem with the reproducibility of the radii ratio method. In order to describe the curvature of the basal and apical turns, Manoussaki et al. (2008) used five equally spaced points on the first quarter of basal and last quarter of the apical turn on an orthogonal projection of the path of the basilar membrane in order to determine the center of curvature and radius for each of the turns individually. This way, actual curvature is taken into consideration. This procedure is mimicked in our study by calculating the respective radii based on 2-D coordinates of three points on the most basal and most apical quarter turns (Fig. 1c).

A different procedure to determine basal and apical radii was used by Chadwick et al. (2006), Ekdale and Racicot (2015), and Ketten et al. (2016). These authors connected one point at the basal end and one point at the apical end of the basilar membrane each to a common center, positioned either at the center of the spiral or at the center of the modiolus, in an orthogonal 2-D projection of the cochlea. This procedure is a mere connection of points and has little to do with the actual curvature of the respective turns. Furthermore, all three points (basal, apical, and central) were determined differently by all three working groups; for example, the apical point is either at the minimum distance to the center (Chadwick et al., 2006), at the tip of the apex (Ekdale and Racicot, 2015), or at the center of the basilar membrane at the helicotrema (Ketten et al., 2016). The radii yielded by these various approaches are not comparable or interchangeable with each other. Furthermore, these various approaches possibly lead to different radii ratios of curvature calculated for Balaenoptera musculus: 4.8 (Chadwick et al., 2006), 10.5 (Ketten et al., 2016), and 5.6 in our study. Estimating LF hearing limits by using the ratio of the radii of curvature from the most basal and most apical turn of the cochlea is thus a delicate issue. Nonetheless, Ekdale and Racicot (2015) and Park et al. (2017) used the radii measured with their own technique but the equation derived by Manoussaki et al. (2008) to estimate the frequency limits of extinct and extant cetaceans. Therefore, we suggest that their implied infrasonic hearing limit for the archaeocete Zygorhiza kochii (8 or $10 \mathrm{~Hz}$, respectively) and for some toothed mysticetes (Park et al., 2017: table 1) be reevaluated, and that the application of the radii ratio method be standardized. 
It is hard to tell whether it is due to this reproducibility issue of the radii ratio method that we were not able to correlate radii ratio with LF hearing limit. Manoussaki et al. (2008) stated that their method might only be applicable to hearing generalists (potentially excluding LF hearing specialists). However, Ketten et al. (2016), using the single-center approach, were able to show a connection between radii ratio and LF limit for Mysticeti.

Our study is not the first one to use cochlear coiling shape (termed "cochlear shape" by Wannaprasert and Jeffery, 2015). Wannaprasert and Jeffery (2015) used a similar mode of extracting coiling information from CT scans, but their method differs from ours in several details: First of all, our data were not initially intended to be used for shape analysis, but only for calculation of radii ratio and cochlear length. Therefore, coordinates of the initial landmarks that were placed on the resliced CT images were not available, and we had to implement the extra step of exporting a tubeshaped spiral and placing landmarks onto it. Wannaprasert and Jeffery (2015) apparently deduced their shape information directly from CT images, which, admittedly, makes their approach less prone to user errors. However, they only used $22.5^{\circ}$ increments to capture the coiling shape, whereas we used increments of $2^{\circ}$, resulting in a much more precise representation of cochlear coiling geometry. Also, Wannaprasert and Jeffery (2015) used "the center of the cochlear cavity" (Wannaprasert and Jeffery, 2015: p. 43) to place the initial landmarks in each slice, whereas we used a more precise and reproducible location, namely the point exactly halfway between the primary and secondary bony laminae. Therefore, we assume that we provided valuable improvement in terms of accuracy and reproducibility for the method introduced by Wannaprasert and Jeffery (2015).

\section{Conclusions}

Based on the results of our analysis of cochlear coiling shape, shape change along the PC axes (Fig. 2) suggests that a shift of the frequency range towards the lower end, including the ability to hear very low and infrasonic frequencies, is associated with compact coiling, a nongradual ascent of the basilar membrane, the basal end of the basilar membrane below the level of the basal turn, the second turn protruding over the basal turn, a descending apex, and a high number of turns (2.2 or above). Furthermore, low LF limits occur in cetaceans with longer cochleae and relatively larger cranial widths (PC3 of symmetric cranial shape).

Frequency ranges at the higher end of the cetacean spectrum, including the use of ultrasound, as well as regularly coiled, shorter cochleae with fewer turns, and a lower radii ratio, are clearly tied to the odontocete cranial shape featuring extreme posterior shift and shortening of the nasals (telescoping) and cranial asymmetry (a larger right side of the cranium).
Very low-frequency hearing $(50 \mathrm{~Hz}$ and below) had likely evolved by the middle Miocene, and infrasonic hearing (below $20 \mathrm{~Hz}$ ) had evolved by the late Miocene. Even the earliest Mysticeti were probably able to hear frequencies of $100 \mathrm{~Hz}$ and below, and the ability to hear low frequencies within the human audible range may be ancestral to all Neoceti.

Cochlear coiling shape proved useful for inferring hearing range, as did number of turns and cochlear length times number of turns. Radii ratio is not directly connected to LF hearing in our study, and to date the method has not been used in a standardized, comparable manner.

Data availability. Micro-CT data and related metadata are archived at the Helmholtz-Zentrum Berlin für Materialien und Energie. Additional data (morphometrics, PCAs, imaging, statistics) can be accessed through the Museum für Naturkunde - Leibniz-Institut für Evolutions- und Biodiversitätsforschung in Berlin, Germany.

Competing interests. The authors declare that they have no conflict of interest.

Special issue statement. This article is part of the special issue "Secondary adaptation of tetrapods to life in water - Proceedings of the 8th International Meeting, Berlin 2017". It is a result of the 8th International Meeting on the Secondary Adaptation of Tetrapods to Life in Water, Berlin, Germany, 3-8 April 2017.

Acknowledgements. We kindly thank the following persons and institutions for access to specimens: David J. Bohaska and Nicholas D. Pyenson (USNM), Mark Bosselaers (Royal Zeeland Society of Science, Middelburg, the Netherlands; IRSNB), Mark T. Clementz (University of Wyoming, Laramie, WY), Ellen Horstrup (SBMB), Annelise Folie and Olivier Lambert (IRSNB), Frieder Mayer and Detlef Willborn (ZMB_MAM), Jennifer McCormick (ChM), Christian de Muizon (MNHN), Morten Tange Olsen (CN), Klaas Post (NMR), and J. G. M. "Hans" Thewissen (NEOMED). We are indebted to Nikolay Kardjilov (Helmholtz-Zentrum Berlin) for support of micro-CT scanning, reconstruction, and visualization. We would also like to express our cordial thanks to Olivier Lambert (Institut royal des Sciences naturelles de Belgique, Brussels) and Benjamin Ramassamy (Museum Sønderjylland, Gram, Denmark) for their critical and helpful reviews of the manuscript, plus Eric G. Ekdale (San Diego State University) and Thomas Deméré (San Diego Natural History Museum) for commenting on an earlier version of the manuscript. Funding was provided by the Deutsche Forschungsgemeinschaft (DFG HA 1776/13-1, DFG FA 889/2-1, and DFG BA 1170/25-1).

Edited by: Florian Witzmann

Reviewed by: Olivier Lambert and Benjamin Ramassamy 


\section{References}

Adams, D. C., Rohlf, F. J., and Slice, D. E.: A field comes of age: geometric morphometrics in the 21st century, Hystrix, 24, 7-14, 2013.

Awbrey, F. T., Thomas, J. A., and Kastelein, R. A.: Low-frequency underwater hearing sensitivity in belugas, Delphinapterus leucas, J. Acoust. Soc. Amer., 109, 1717-1722, 1988.

Backus, R. H. and Schevill, W. E.: Physeter clicks, in: Whales, dolphins and porpoises, edited by: Norris, K. S., Univ. California Press, Berkeley, 510-528, 1966.

Beamish, P. and Mitchell, E.: Ultrasonic sounds recorded in the presence of a blue whale Balanoptera musculus, Deep-Sea Res., 18, 803-809, 1971.

Blomqvist, C. and Amundin, M.: High-frequency burst-pulse sounds in agonistic/agressive interactions in Bottlenose dolphins, Tursiops truncatus, in: Echolocation in bats and dolphins, edited by: Thomas, J. A., Moss, C. F., and Vater, M., University Press, Chicago, 425-431, 2004.

Boessenecker, R. W. and Fordyce, R. E.: A new genus and species of eomysticetid (Cetacea: Mysticeti) and a reinterpretation of 'Mauicetus' lophocephalus Marples, 1956: Transitional baleen whales from the upper Oligocene of New Zealand, Zool. J. Linnean Soc., 175, 607-660, 2015.

Castellote, M., Mooney, T. A., Quakenbush, L., Hobbs, R., Goertz, C., and Gaglione, E.: Baseline hearing abilities and variability in wild beluga whales (Delphinapterus leucas), J. Exp. Biol., 217, 1682-1691, 2014.

Chadwick, R. S., Manoussaki, D., Dimitriadis, E. K., Shoelson, B., Ketten, D. R., Arruda, J., and O'Malley, J. T.: Cochlear coiling and low-frequency hearing, in: Auditory mechanisms: Processes and models, Nuttall, A. L., Ren, T., Gillespie, P., Grosh, K., and de Broer, E., World Scientific Publishing, Singapore, 417-424, 2006.

Churchill M., Martínez-Cáceres, M., de Muizon, C., Mnieckowski, J., and Geisler, J. H.: The origin of high-frequency hearing in whales, Current Biol., 26, 2144-2149, 2016.

Cummings, W. C. and Holliday, D. V.: Sounds and source levels from bowhead whales off Pt. Barrow, Alaska, J. Acoust. Soc. Amer., 82, 814-821, 1987.

Cranford, T. W. and Krysl, P.: Fin whale sound reception mechanisms: Skull vibration enables lowfrequency hearing, PLoS ONE, 10, e0116222, 1-17, https://doi.org/10.1371/journal.pone.0116222, 2015.

Erbe, C.: Hearing abilities of baleen whales, Defense R\&D Canada Atlantic Contractor Report, 2002-065, 1-28, 2002.

Ekdale, E. G.: Morphological variation among the inner ears of extinct and extant baleen whales (Cetacea: Mysticeti), J. Morphol., 277, 1599-1615, 2016.

Ekdale, E. G. and Racicot, R. A.: Anatomical evidence for low frequency sensitivity in an archaeocete whale: Comparison of the inner ear of Zygorhiza kochii with that of crown Mysticeti, J. Anat., 226, 22-39, 2015.

Fahlke, J. M. and Hampe, O.: Cranial symmetry in baleen whales (Cetacea, Mysticeti) and the occurrence of cranial asymmetry throughout cetacean evolution, Naturwiss., 102, 1-16, 2015.

Fahlke, J. M., Gingerich, P. D., Welsh, R. C., and Wood, A. R.: Cranial asymmetry in Eocene archaeocete whales and the evolution of directional hearing in water, P. Natl. Acad. Sci., 108, 1454514548, 2011.
Fleischer, G.: Studien am Skelett des Gehörorgans der Säugetiere, einschließlich des Menschen, Säugetierkundl. Mitt., 21, 131239, 1973.

Fleischer, G.: Hearing in extinct cetaceans as determined by cochlear structure, J. Paleont., 50, 133-152, 1976a.

Fleischer, G.: Über die Beziehungen zwischen Hörvermögen und Schädelbau bei Walen, Säugetierkundl. Mitt., 24, 48-59, 1976 b.

Fleischer, G.: Evolutionary principles of the mammalian middle ear, Adv. Anat. Embryol. Cell Biol., 55, 3-70, 1978.

Gedamke, J., Costa, D. P., and Dunstan, A.: Localization and visual verification of a complex minke whale vocalization, J. Acoust. Soc. Amer., 109, 3038-3047, 2001.

Hammer, Ø., Harper, D. A. T., and Ryan, P. D.: PAST: Paleontological statistics software package for education and data analysis, Palaeontol. Electronica, 4, 1-9, 2001.

Hampe, O. and Ritsche, I.: Die Bartenwalfauna (Cetacea: Mysticeti: Balaenomorpha) aus dem Lüneburgium (Serravallium, Mittelmiozän) von Freetz bei Sittensen (Niedersachsen, Deutschland), Z. geol. Wiss., 39, 83-110, 2011.

Heffner, H. E. and Heffner, R. S.: High-frequency hearing, in: Handbook of the senses: Audition, edited by: Dallos, P., Oertel, D., and Hoy, R., Elsevier, New York, 55-60, 2008.

Herzing, D. L.: Acoustics and social behaviour of wild dolphins: Implications for a sound society, in: Hearing by whales and dolphins, edited by: Au, W. W. L., Popper, A. N., and Fay, R. R., Springer, New York, 225-272, 2000.

Johnson, C. S.: Auditory threshold of the bottlenosed porpoise (Tursiops truncatus, Montagu), NOTS Techn. Publ., 4178, U.S. Naval Ordonance Test Station, China Lake, CA, 1966.

Johnson, C. S., McManus, M. W., and Skaar, D.: Masked tonal hearing thresholds in the beluga whale, J. Acoust. Soc. Amer., 85, 2651-2654, 1989.

Kardjilov, N., Hilger, A., Manke, I., Woracek, R., and Banhart, J.: CONRAD-2: the new neutron imaging instrument at the Helmholtz-Zentrum Berlin, J. Applied Crystallogr., 49, 195-202, 2016.

Karlsen, J. D., Bisther, A., Lydersen, C., Haug, T., and Kovacs, K. M.: Summer vocalizations of adult male white whales (Delphinapterus leucas) in Svalbard, Norway, Polar Biol., 25, 808-817, 2002.

Ketten, D. R.: The cetacean ear: Form, frequency and evolution, in: Marine mammal sensory systems, edited by: Thomas, J. A., Kastelein, R. A., and Supin, A. Y., Plenum Press, New York, 5375, 1992.

Ketten, D. R.: Functional analysis of whale ears: Adaptations for underwater hearing, IEEE Proc. Underwater Acoust., 1, 264270, 1994.

Ketten, D. R., Arruda, J., Cramer, S., and Yamato, M.: Great ears: Low-frequency sensitivity correlates in land and marine leviathans, in: The effects of noise on aquatic life II. Advances in Medicine and Biology, 875, edited by: Popper, A. N. and Hawkins, A., Springer, New York, 529-538, 2016.

Klingenberg, C. P.: MorphoJ: An integrated software package for geometric morphometrics, Molecular Ecol. Resources, 11, 353357, 2011.

Madsen, P. T., Wahlberg, M., and Møhl, B.: Male sperm whale (Physeter macrocephalus) acoustics in a high-latitude habitat: implications for echolocation and communication, Behavioral Ecol. Sociobiol., 53, 31-41, 2002. 
Manoussaki, D., Dimitriadis, E. K., and Chadwick, R. S.: Cochlea's graded curvature effect on low frequency waves, Phys. Rev. Lett., 96, 1-4, 2006.

Manoussaki, D., Chadwick, R. S., Ketten, D. R., Arruda, J., Dimitriadis, E. K., and O'Malley, J. T.: The influence of cochlear shape on low-frequency hearing, P. Natl. Acad. Sci., 105, 6162-6166, 2008.

Marx, F. G. and Fordyce, R. E.: Baleen boom and bust: A synthesis of mysticete phylogeny, diversity and disparity, R. Soc. open sci., 2, 140434, https://doi.org/10.1098/rsos.140434, 2015.

Marx, F. G., Lambert, O., and Uhen, M. D.: Cetacean Paleobiology, Wiley, Chichester, UK, 2016.

Mellinger, D. K. and Clark, C. W.: Blue whale (Balaenoptera musculus) sounds from the North Atlantic, J. Acoust. Soc. Amer., 114, 1108-1119, 2003.

Miller, G. S.: The telescoping of the cetacean skull, Smithsonian Misc. Coll., 76, 1-71, 1923.

Mishima,Y., Morisaka, T., Itoh, M., Matsuo, I., Sakaguchi, A., and Miyamoto, Y.: Individuality embedded in the isolation calls of captive beluga whales (Delphinapterus leucas), Zool. Lett., 1, 27, https://doi.org/10.1186/s40851-015-0028-x, 2015.

Mitteroecker, P. and Gunz, P.: Advances in geometric morphometrics, Evol. Biol., 36, 235-247, 2009.

Møller, H. and Pedersen, C. S.: Hearing at low and infrasonic frequencies, Noise Health, 6, 37-57, 2004.

Mourlam, M. J. and Orliac, M. J.: Infrasonic and ultrasonic hearing evolved after the emergence of modern whales, Current Biol., 27, 1776-1781, 2017.

Nedwell, J. R., Edwards, B., Turnpenny, A. W. H., and Gordon, J.: Fish and marine mammal audiograms: A summary of available information, Subacoustech Rep., 534R0214, Hampshire, 2004.

Nummela, S., Thewissen, J. G. M., Bajpai, S., Hussain, S. T., and Kumar, K.: Eocene evolution of whale hearing, Nature, 430, 776-778, 2004.

Nummela, S., Thewissen, J. G. M., Bajpai, S., Hussain, S. T., and Kumar, K.: Sound transmission in archaic and modern whales: anatomical adaptations for underwater hearing, Anat. Rec., 290, 716-733, 2007.

Park, T., Evans, A. R., Gallagher, S. J., and Fitzgerald, E. M. G.: Low-frequency hearing preceded the evolution of giant bodysize and filter feeding in baleen whales, Proc. Roy. Soc. B, 284, 20162528, https://doi.org/10.1098/rspb.2016.2528, 2017.
Steeman, M. E.: Cladistic analysis and a revised classification of fossil and recent mysticetes, Zool. J. Linnean Soc., 150, 875894, 2007.

Steeman, M. E.: The extinct baleen whale fauna from the MiocenePliocene of Belgium and the diagnostic cetacean ear bones, J. Syst. Palaeont., 8, 63-80, 2010.

Thompson, P. O., Cummings, W. C., and Ha, D. J.: Sounds, source levels, and associated behavior of humpback whales, Southeast Alaska, J. Acoust. Soc. Amer., 80, 735-740, 1986.

Tubelli, A. A., Zosuls, A., Ketten, D. R., Yamato, M., and Mountain, D. C.: A prediction of the minke whale (Balaenoptera acutorostrata) middle-ear transfer function, J. Acoust. Soc. Amer., 132, 3263-3272, 2012.

Turl, C. W.: Low-frequency sound detection by a bottlenose dolphin, J. Acoust. Soc. Amer., 94, 3006-3008, 1993.

Uhen, M. D.: Form, function, and anatomy of Dorudon atrox (Mammalia, Cetacea): An archaeocete from the middle to late Eocene of Egypt, Univ. Michigan Pap. Paleontol., 34, 1-222, 2004.

Vater, M., Meng, J., and Fox, R. C.: Hearing organ evolution and specialization: Early and later mammals, in: Evolution of the vertebrate auditory system, edited by: Manley, G. A., Popper, A. N., and Fay, R. R., Springer, New York, 256-288, 2004.

Wannaprasert, T. and Jeffery, N.: Variations of mammalian cochlear shape in relation to hearing frequency and skull size, Tropical Nat. Hist., 15, 41-54, 2015.

Wartzok, D. and Ketten, D. R.: Marine mammal sensory systems, in: Biology of marine mammals, edited by: Reynolds III, J. E. and Rommel, S. A., Smithsonian Inst. Press, Washington, D.C., 117-175, 1999.

West, C. D.: The relationship of the spiral turns of the cochlea and the length of the basilar membrane to the range of audible frequencies in ground dwelling mammals, J. Acousti. Soc. Amer., 77, 1091-1101, 1985.

Yamato, M., Ketten, D. R., Arruda, J., Cramer, S., and Moore, K.: The auditory anatomy of the minke whale (Balaenoptera acutorostrata): A potential fatty sound reception pathway in a baleen whale, Anat. Rec., 295, 991-998, 2012.

Zelditch, M. L., Swiderski, D. L., and Sheets, H. D.: Geometric morphometrics for biologists: A primer, 2nd edition, Elsevier Acad. Press, London, 2012. 